STRUCTURAL SCIENCE CRYSTAL ENGINEERING MATERIALS

ISSN 2052-5206

Keywords: book review; crystallographic group theory; symmetry of crystals

\section{Symmetry relationships between crystal structures. By Ulrich Müller. IUCr/Oxford Science Publications. 2017. Paperback Pp. 352. Price GBP 29.99. ISBN 9780198807209}

\author{
Massimo Nespolo*
}

Université de Lorraine, CNRS, CRM2, Nancy, France. *Correspondence e-mail: massimo.nespolo@univ-lorraine.fr

This is the paperback edition of the book published four years ago in hardback. The lighter (both in the terms of weight and of price) version is certainly to be welcomed, especially by students who will greatly benefit having a personal copy of this indispensable reference textbook. Readers will also appreciate the correction of the few typos I had pointed out in my detailed review (Nespolo, 2013).

\section{References}

Nespolo, M. (2013). Acta Cryst. B69, 524-526.

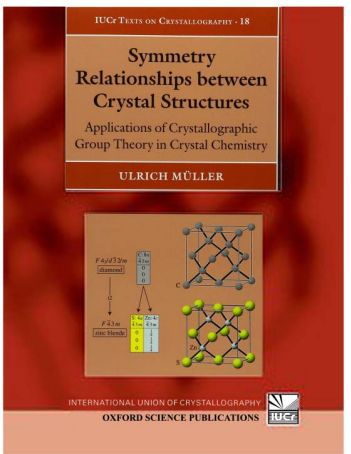

